\title{
Role of Environment in Connecting Disabled and Abandoned Children to Society (A case Study of Turning Rofaydeh Welfare Complex Project into a House in a Neighborhood Park)
}

\author{
Fateme Yarmohammad ${ }^{1}$ \\ ${ }^{1}$ Institute for Management and Planning Studies, Tehran, Iran \\ Correspondence: Fateme Yarmohammad, Institute for Management and Planning Studies, Shahid Mokhtar \\ Asgary) Jamal Abad) St., No.6, Tehran, Iran. E-mail: fateme.yarmohammad@gmail.com
}

Received: January 20, 2016

doi:10.5539/mas.v10n5p121
Accepted: February 23, 2016

Online Published: April 2, 2016

URL: http://dx.doi.org/10.5539/mas.v10n5p121

\begin{abstract}
Due to physical and mental disability, children tend to withdraw themselves from society especially if their parents abandon them, and if society fail to establish a suitable relationship with these children, their presence will uproot from society. In this paper, we deals with the case Rofaydeh Welfare Services Complex in Iran in the he city of Tehran where 60 disabled, mentally or physically disabled children are taken care of, some of them were also orphans. The aim of the article is to provide an environment which is conducive to more relationship and interaction of these children with members of society with regard to their lack of caretaker and family, as well as protecting the primacy of the children's living spaces as their home.

The research methodology included library and field methods; thus, suitable strategies were developed to achieve the goal of this paper. The research indicates that designing the complex as a house in the middle of the neighborhood park allows for children's presence in the society among the people and close interaction with people through being positioned in a neighborhood park, as well as providing the presence of the children in a space similar to a house which is every child's wish. On neighborhood scale, the park protects the children from social damages so that they feel sense of intimacy working between them and people.
\end{abstract}

Keywords: environment, house, park of the neighborhood, the disabled's relationship with society

\section{Introduction}

According to UNICEF Children with disabilities are one of the most marginalized and excluded groups in society. Facing daily discrimination in the form of negative attitudes, lack of adequate policies and legislation, they are effectively barred from realizing their rights to healthcare, education, and even survival.

In this regard, every year there are children who come to this world as they suffer from mental or physical defection or both due to lack of parents' knowledge about scientific and sanitary issues or the failure to comply with physical and mental sanitation during pregnancy.

Since the cost of care and protection of these children is high, many of these children are left on their own in their early childhood due to parents' financial inability. The children are often sent to welfare organizations so that they are under the care of the organization. Since the individuals cannot play an influential role in the society like everybody else, and society sustain huge expenses, they are often treated like outcasts as nobody takes notice of their needs and they are considered as a burden on society.

Meanwhile, if these children are provided with suitable living conditions emotionally as well as care, educational, cultural, and social facilities, they can work as an influential member in the society and play a useful role.

Rofaydeh Welfare Services Complex is one of the centers taking care of children who suffer from lack of parental affection as well as mental and physical defections. Sadly, the complex faces may deficiencies in order to care and nurture these children as in lack of proper environment and essential facilities that lead to adverse living circumstance for the children.

\subsection{Introduction of Rofaydeh Welfare Services Complex}

Rofaydeh Welfare Services Complex located in the city of Tehran, the capital of Iran, is a place where about 60 
disabled children of society, some of whom are orphans as well, are under protection and rehabilitation services.

The complex is built that covers an area of 6000 square meters on two separate buildings; the south building which is older include two stories on the ground floor and one basement with an area of 4427 square meters which is under demolition process due to its old age. The South Building Show in Figure 1.

The north building built after the Revolution covers an area of 1035 square meters with two stories, the ground floor and the basement. The North Building Show in Figure 2.

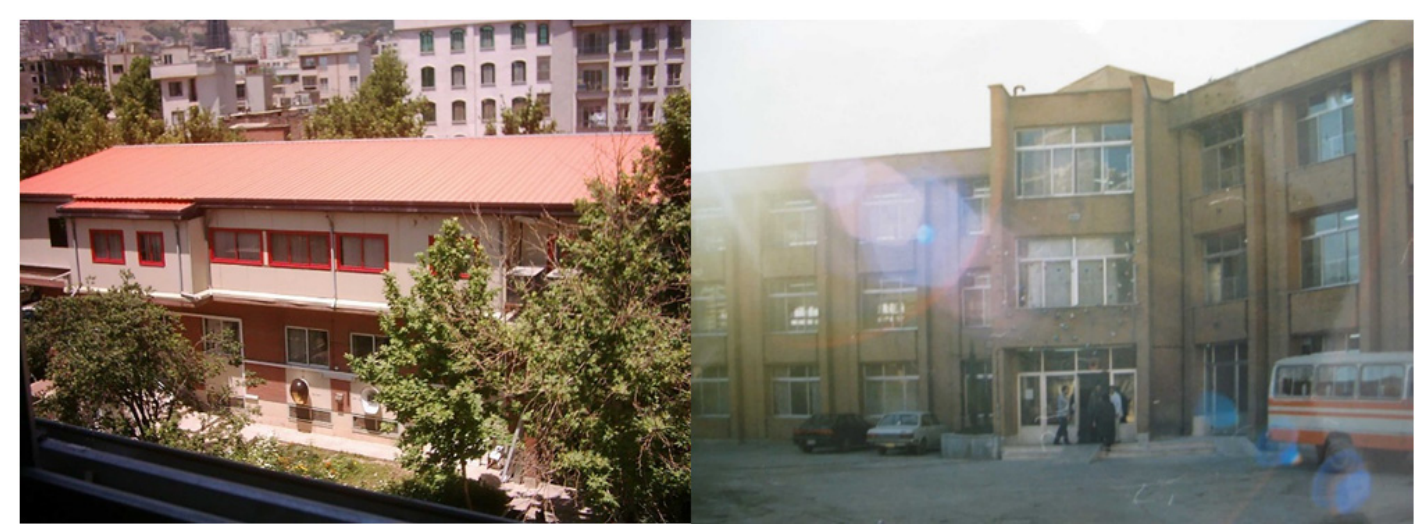

Figure 1. The South Building
Figure 2. The North Building

The ground floor is composed of administrative, social and kindergarten wards as the basement includes warehouse, service room, tailor home, halls and children care wards. The Child Care Spaces Show in Figure 3.
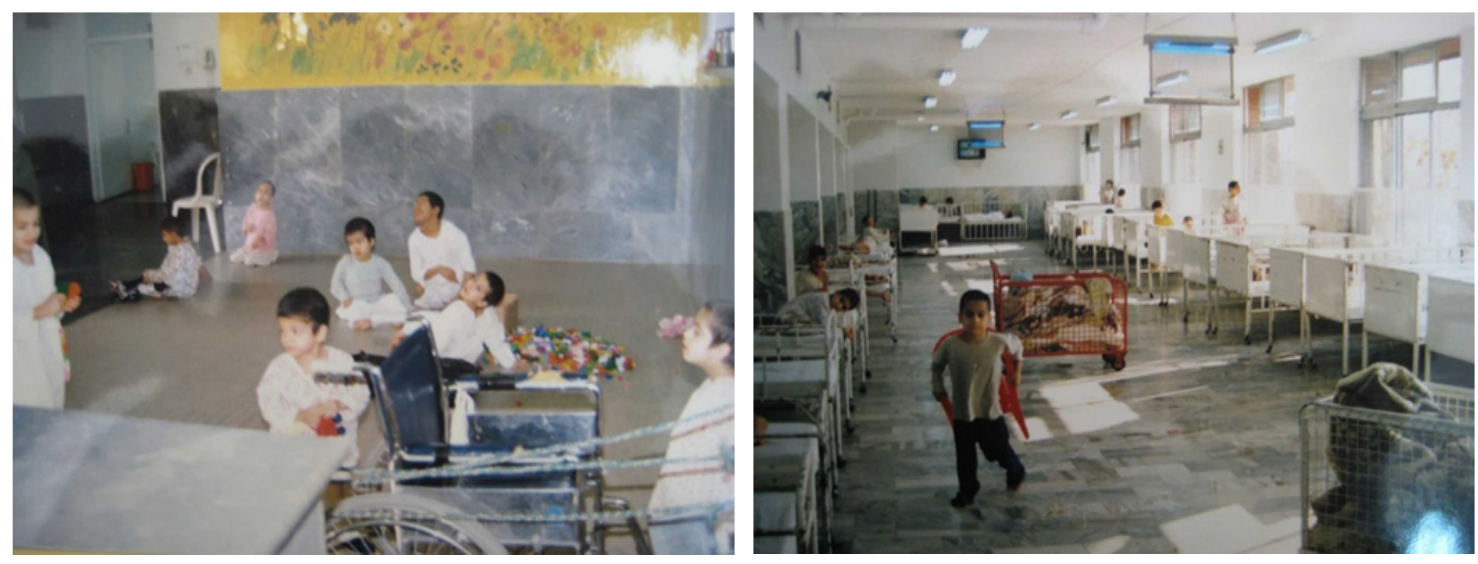

Figure 3. The Child Care Spaces

An area of about 2650 square meters is intended for open space where less than 600 is earmarked for green space.

The observations suggest that one of the most important problems and concerns of the children is lack of love and the agony that they sustain with their physical defect because of lack of family presence beside them, in the sense that they hold on to your hands firmly and want you no to leave them when you come to see them.

The design of the environment and interior and exterior spaces is in such a way that the connection of the children to society and others is cut off as they are locked up in the space.

\section{Significance of the Study}

The society has looked upon Children with Disabilities as outsiders for Centuries. All children who don't seem quite right in one way or another has been made fun of, held back, harassed, cut off from reality, pushed aside, 
hospitalized, and ignored for so long that we as a society should be totally ashamed of ourselves. We celebrate Our Freedom on Independence Day, but has anyone ever thought about what kind of freedom we offer those with Disabilities. Something to think about.

Every person should have the chance of their own independence. We need to help the children with Disabilities get a chance at life that we all take for granted. Each child born with a disability is dependent on someone for the rest of their life, almost always. But in todays' Society we could help these children find their place in life and let them have opportunities, just like we have. Just because some children look a little different, walk a little different, talk a little different, and act a little different. What right do we have to continually hold these children back from reaching goals and being productive in some manner? (Hamm, 1999)

Research shows "that little has been published about the impact of environmental factors on community participation. Many studies do not clearly define the concept of community participation. Research on the impact of environmental factors on community participation so far seems not to be based on a theoretical framework. Most studies focused on the impact of services on community participation in general"(Verdonschot, de Witte , Reichrath , Buntinx \& Curfs , 2009)

Given the significance of the subject and little studies conducted until now into the role of environment in disabled children's relationship with society, and since the children are deprived of family blessing as well as their physical and mental disability, it is necessary to conduct vast studies in this regard.

\section{Research Background}

Studies conducted up to now should be addressed from two aspects:

1- Considering the need to live in the home-like environment and environmental conditions and its related environmental circumstances

2- Considering the need to communicate with individuals and society and its related environmental circumstances

As for the above, we can refer to the research conducted as follows;

Disabled children and young people spend more time at home than non-disabled children, which means that their home environment is even more important to this group of children. (Beresford, 2006)

There is evidence to suggest, however, that disabled children's homes are the most restrictive environments in which they spend time. (Oldham \& Beresford, 1998)

Oldham and Beresford (1998) found that disabled children wanted to be able to access all parts of their home, including the garden. When asked about their 'ideal home', all the children mentioned having greater space within the house and having a garden.

Research shows that unsuitable housing can prevent babies and children being discharged home following birth or significant and traumatic injury, resulting in very prolonged stays in hospital. (Noyes, 2002)

By contrast, suitable housing promotes independence and life skills which disabled children value.

On the contrary, there is a significant relationship between child's affective relationship with adults and his emotional growth. For instance, Zarrati (2005) found a positive correlation between secure attachment and emotional intelligence as well as a negative correlation between insecure, anxious-ambivalent, and avoidant attachment and intelligence. Moreover, Kafetsios (2004), Kirkoririan (2002), Bekendam (2001), Fullam (2002) and Tomps (2001) achieved the similar results which suggest the theoretical explanation of the relationship between emotional intelligence and attachment and child's interpersonal relationships with his parent (quoted by Colman et al., 2000).

Furthermore, there is a significant relationship between child's living environment and his intelligence growth; people who benefit from affective life have better psychological health and emotional intelligence as they hold a positive attitude to life (Ghanbarihashemabadi, 2011).

Normal children have significantly higher emotional intelligence than children who grow up in orphanage. According to Bendowra (1997, quoted by Schultz, 2009), children learn invaluable information and social skills through observing and emulating their parents. However, Oldham (2003) holds that children can learn the pillars of social and emotional intelligence through observation.

Studies by some psychologists have shown that three-year stay in the orphanage, almost between six months to three years and six month old) is on an average conducive to an IQ score of 72, while a similar group of orphanage children show an IQ score of 100 when they are adopted by a family and benefit from a natural 
environment. The results of IQ test on ten-year old orphanage children or older demonstrated that the effect of poor mental environment is more stable in early life. IQ score change very little after 12 to 15 years of age. In other words, a child who spend his early life in poor mental conditions will be never able to compensate for his lack of intelligence (Mohammadi).

This jeopardize the issue of disabled children and orphans twice as much as expected. Under such circumstances, people are in charge of caring and supporting, in that they have to view them as divine trust, and stop the causes that hurt, humiliate and mock them or are considered as their ethical problems and deviation, by knowing that he is the divine trust in their hands and avoid feeling pity for them. Since the children are casted aside by their parents due to mental and physical defects or for other reasons such as economic deprivation, sympathetic mentors and staff are burdened with the parental duties, and the need for financial and emotional support by society and people is felt further (Iran Salamat website, 2005).

"Social relations can exert a profound effect on the disabled individual's attitudes toward himself and opportunities that he achieve in order to obtain mental, education and occupation adaptation. If the reaction of relatives is based on fear, rejection or discrimination, he may use up his much of energy for hiding his discrepancies.

If reactions consist in feeling of pity for child and his inability, he typically considers himself as individual who rely on everyone. However, if people consider the disabled children as individuals who are the same as others in most cases, even though they have some limitations, they will be encouraged to grow up as independent individuals and useful members for a society" (Farjad, S. 2014; 132).

Until now, a number of theses have been written in this respect and obtained similar results in order to promote children's social relationship and their link with society through integration of the children's living space into the center of urban neighborhoods; "spaces for abandoned children's life in conjunction with an urban neighborhood center" and "I have a house in the city; design of accommodation and care units for orphans", to name a few.

Searching identified 1232 articles and 31 met the inclusion criteria. Each domain of the environment within the ICF (the International Classification of Functioning, Disability and Health) influenced participation as a facilitator and/or barrier. The most common facilitators involved social support of family and friends and geographic location. The most common barriers included attitudes, physical environment, transportation, policies and the lack of support from staff and service providers. (Anaby, Hand, Bradley, DiRezze, Forhan, DiGiacomo \& Law, 2013)

But what has been less considered is a double problem that threaten the children, namely their disability and lack of a caretaker; for the latter, unfortunately there are quite few studies into these children as design of such bases have been rarely decided.

\section{Objective and Hypotheses}

The aim of the article is to provide an environment which is conducive to more relationship and interaction of these children with members of society with regard to their lack of caretaker and family, as well as protecting the primacy of the children's living spaces as their home.

To achieve the above goal, the subject should be addressed from two aspects:

The one in terms of site location and its position in the city, and the other how spaces are positioned in the site and their proper organizations in order to achieve the goal.

For the first case, it is assumed that the design of the set is aimed for a neighborhood park, where the potential building(s) of welfare complex (house and clinic) are built to interact with a park.

As for the second case, it is attempted that the design and organization of spaces are made in such a way that their interaction with the environment and individuals is ensured, as well as respecting the privacy of children's life.

\section{Methods}

In order to examine the above hypotheses, the primary investigations included library and field studies.

The studies were carried out in three fields; recognition of behavioral characteristics, studies of physical and sanitary problems and needs, and recognition of the environment and spaces needed for retarded and disabled children.

In the field studies, the presence in the site and close communication with children (60 children in the group age 3 to 10 years old), investigation of their circumstances and how mentors, staff, parents, and other individuals 
seemed necessary. Since most of these children were unable to fill out the questionnaire, and participate in the open discussion or draw a picture, the most effective method was observation and review of their moods, conducts and reactions at close range. Interviews with mentors, social workers, other parents of disabled children, nurses, social psychologists, and neighborhood people were used as other techniques proved effective in conducting the research.

Moreover, library studies included a review of available books and theses, successful examples and cases built and used inside and outside the country in this regard.

\section{Results and Discussion}

The results are offered as presentation of environmental strategies from two aspects--site location and its position in the city, and type of space positioning in the site and their suitable organization. Strategies offered for achieving the goal of the paper and providing proper conditions for children's communication and interaction with society better environmentally, as well as respecting the privacy of children's living spaces and simulating home space for them.

\subsection{Results of Sample Analysis and Study}

1. Building should be situated in green space and green spaces make their ways to them.

2. Studied buildings have courtyard and central green spaces or they are in the center of green open and exterior intertwined spaces.

3. Isolation of living spaces from educational spaces (they can be built in two separate buildings).

4. The height of building should be preferably as high as a story or at most two stories (the upper floor for service spaces).

5. Classification of spaces in order to reduce the scale perceived by children for building

6. Removal of standard and conventional details of any kind and everything associated with an organizational or institutional feeling.

7. Providing spaces in order to educate the children of the institution by trained parents (including the parents of children everyday) and collaborating with mentors (if they will) or volunteers for benevolent actions

8. Direct connection between interior spaces and open spaces

9. Use of the terraces opposite the open space

10. Providing the maximum view from inside to outside with regard to window size and distance to the floor

11. The maximum penetration of light and the role of natural light inside the building

12. Legibility and simplicity of the plan (avoidance from complicated plans including many diversions and detours

13. Building attractive, diverse, simulating and safe spaces.

14. Using simple and comprehensible forms for children

15. Using the combination of fabric with materials

16. Using color combinations (inside and outside)

17. Creating open space inside and isolating different part by home furniture

18. Non-placement of barriers, difference in level, stairs, post and lintel, etc.

19. Building wide corridors with direction signs

20. Placement of continuous signs in order to guide children in open spaces

21. Use of natural materials in the building (knowledge of nature)

22. Developing some measurements for children by some lines containing color, material, and texture

23. Locating administrative section in a place where there is an easy access to it both from outside and from inside (i.e. possibility of direct and permanent control of management over interior spaces)

24. Locating nursing unit near the nursery

25. Considering some facilities to allow for future development

The Space Diagram of Example Studies Show in Figure 4. 


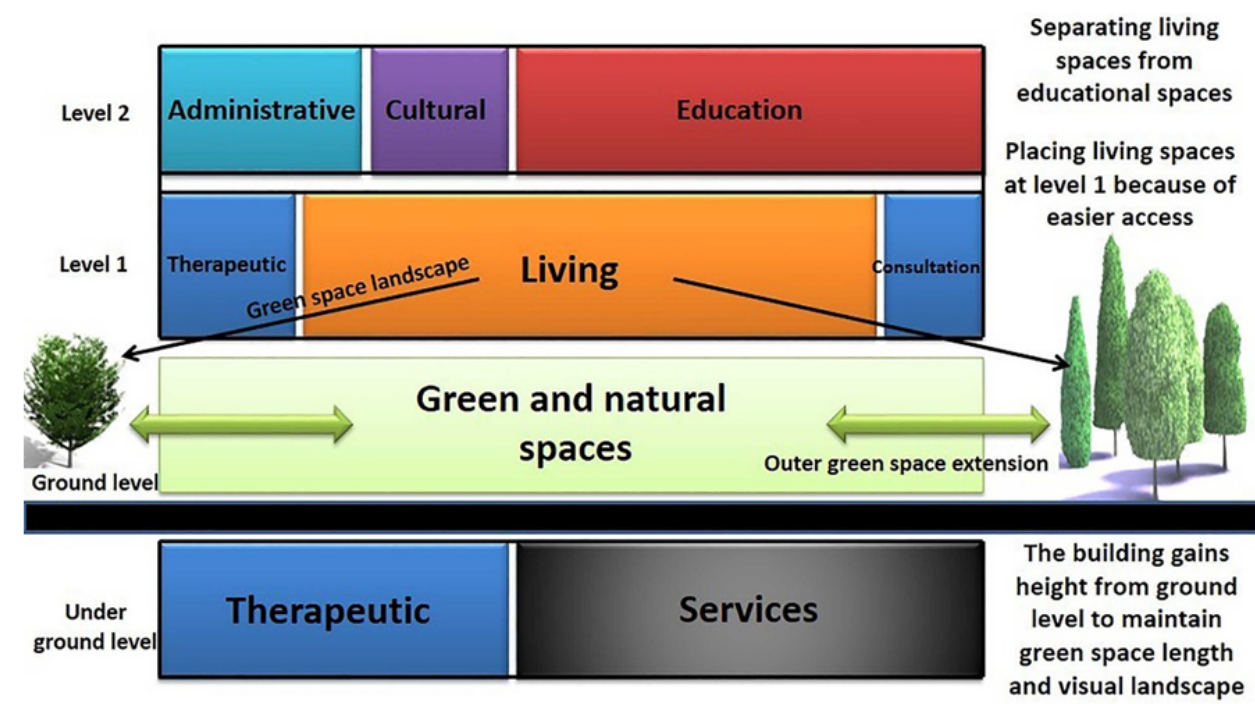

Figure 4. The Space Diagram of Example Studies

\subsection{Results of Project Context Recognition and Climatic Studies}

- A good urban landscape and view in terms of position on the slopes of the Alborze Mountains

- A temperate climate due to the presence of the Alborze Mountains in the north and plain in the south of the region

- Mediterranean and Atlantic humid winds blowing from the west with the average speed of 5.5 meters per second

- By night, cool breeze blows from the mountain (mountain wind), by day wind on the contrary comes from desert (desert wind)

- Rainfall rate is generally low in Tehran and it stands at $245.8 \mathrm{~mm}$ in measurement year, and the number of frost days (with temperatures below zero) was registered to be 36 days in a year.

- Average relative humidity id $46 \%$

- Proper sandy soil

For the above reasons, the setting of the project has good conditions for being turned into park and providing the convenience of living spaces; for this end, the following strategies will have influential role:

1- Use of solar energy in the heating of buildings

- Establishment of building in the maximum radiation direction of solar energy during cold time

-Organization of plan in a way that sunlight penetration to interior spaces is available.

- Prediction of building materials with high thermal capacity

2- Protection of building against sunlight

- Greater use of common walls in complexes and a creating a compact fabric

- Creating perfect shade on the outer side of windows and openings

- Use of proper shade and its position in external spaces in order to be used when the weather is right.

3. Reducing building loss

- covering exterior buildings borders with shrubs and evergreen plants

- Constructing building in the ground or covering the exterior walls with soil

- Providing compact plans

4- Using daily fluctuation in temperature

-Constructing part of building in the ground

-Using thermal insulation in the exterior surfaces 
5- Reducing the effect of wind on heat loss of building

- Providing proper physical forms in terms of the reduced wind effect

- Using different barriers such as trees, walls, and fences

- Setting openings on the back of the wind

6- Protecting building against hot airflow outside

- Providing windows with small sizes

- Providing compact buildings

7- Increasing humidity

- Using elements in the area and water feature in the shade for evaporative cooling

- Using fountains, sprinklers, and garden

- Utilizing indoor and outdoor plant moisturizing

6.3 Results of the Site Recognition

- Location

Rofaydeh Welfare Services Complex, St., Shahid Nemati St., Shahid Baradaran Soleimani, Gheitarieh, District 1, Tehran, Iran

The Location of Rofaydeh Rehabilitation Institute Show in Figure 5.

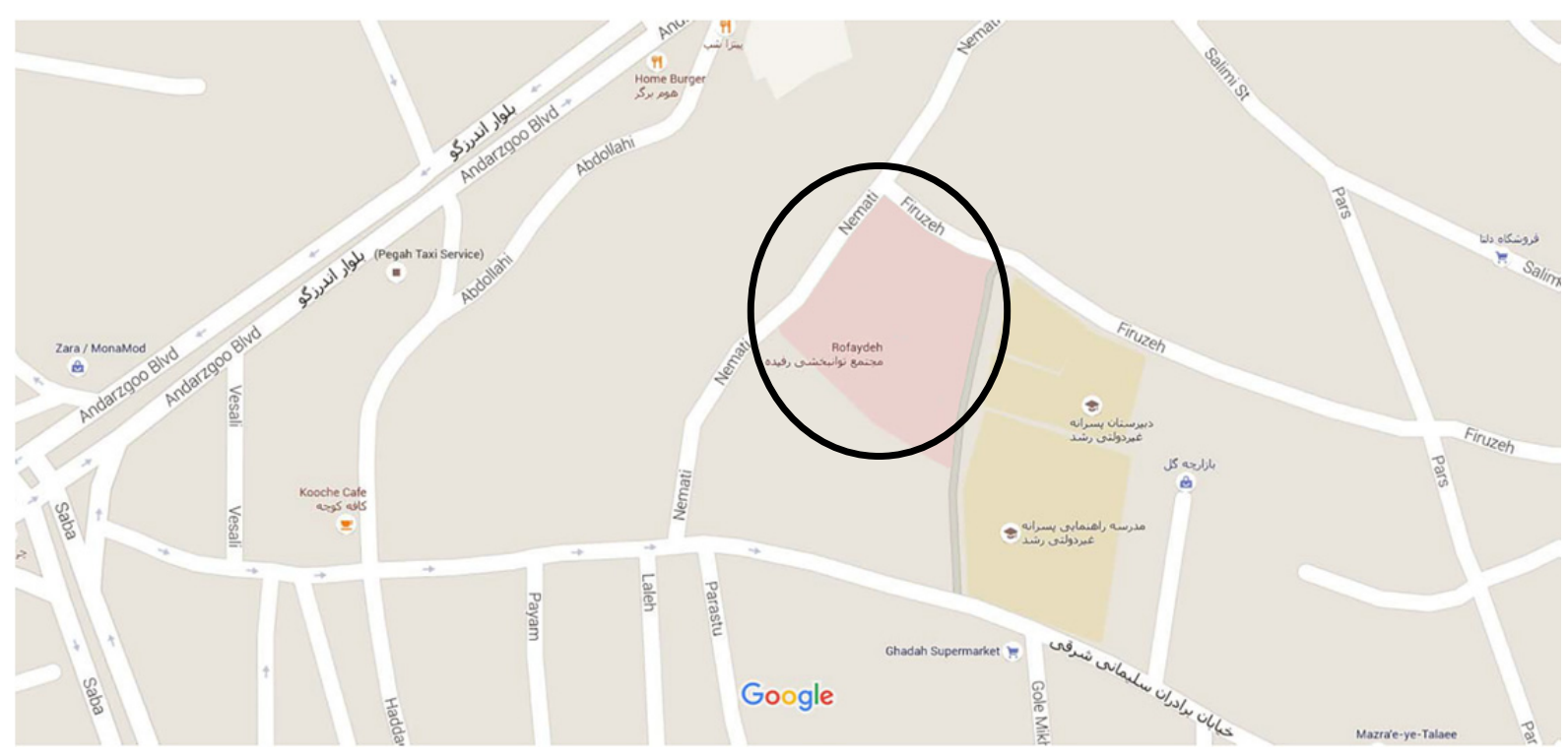

Figure 5. The Location of Rofaydeh Rehabilitation Institute

\section{- Topography}

With appropriate $2 \%$ northern-southern slope, it provides a good level for the disabled children's travelling

- Form and size of the land

It has a trapezoidal form (its south and north side has a fracture as other sides are smooth), which provides a good space with an area of 6046 square meters for establishing park on neighborhood and living spaces scale

- Existing buildings

There are two buildings in the north and south of the land, as the southern one is demolished and the northern one can be used as a clinic.

- Existing trees

Seven trees on the west and south side of the land, and its preservation would help turn the site into park. 
- Neighbors

Most buildings of the neighborhood are densely populated and the number of stories is 5, 6 to 7 .

Site and orientation of adjacent buildings is south west as rotation to the west in the western buildings is more intense. The rotation of southern adjacent buildings is less intense.

- Access

The site is bounded by neighboring walls in the south and east, in the west by Shahid Nemati St. and in the north by Firouzeh Alley, where there is an access to the building from these two sides. A sidewalk with $210 \mathrm{~cm}$ width is located on the western side and a narrow stream with $15 \mathrm{~cm}$ width run alongside (with the existing trees in the western side, the position of building entrance should be taken into account).

- Access to the city's main arteries

The nearest artery of the city to the site in question is Sadr Expressway; through Gheitarieh Exit as it extends as far end as Gheightarieh St., Soleimani St., and then Nemati St., access to the site is possible.

For the above reasons, the site has the necessary potential to be turned into a neighborhood park and attract people with regard to its location in the city and its position in a residential and neighborhood fabric, as well as lack of a park in the neighborhood.

The Location Diagram of Site Studies Show in Figure 6.

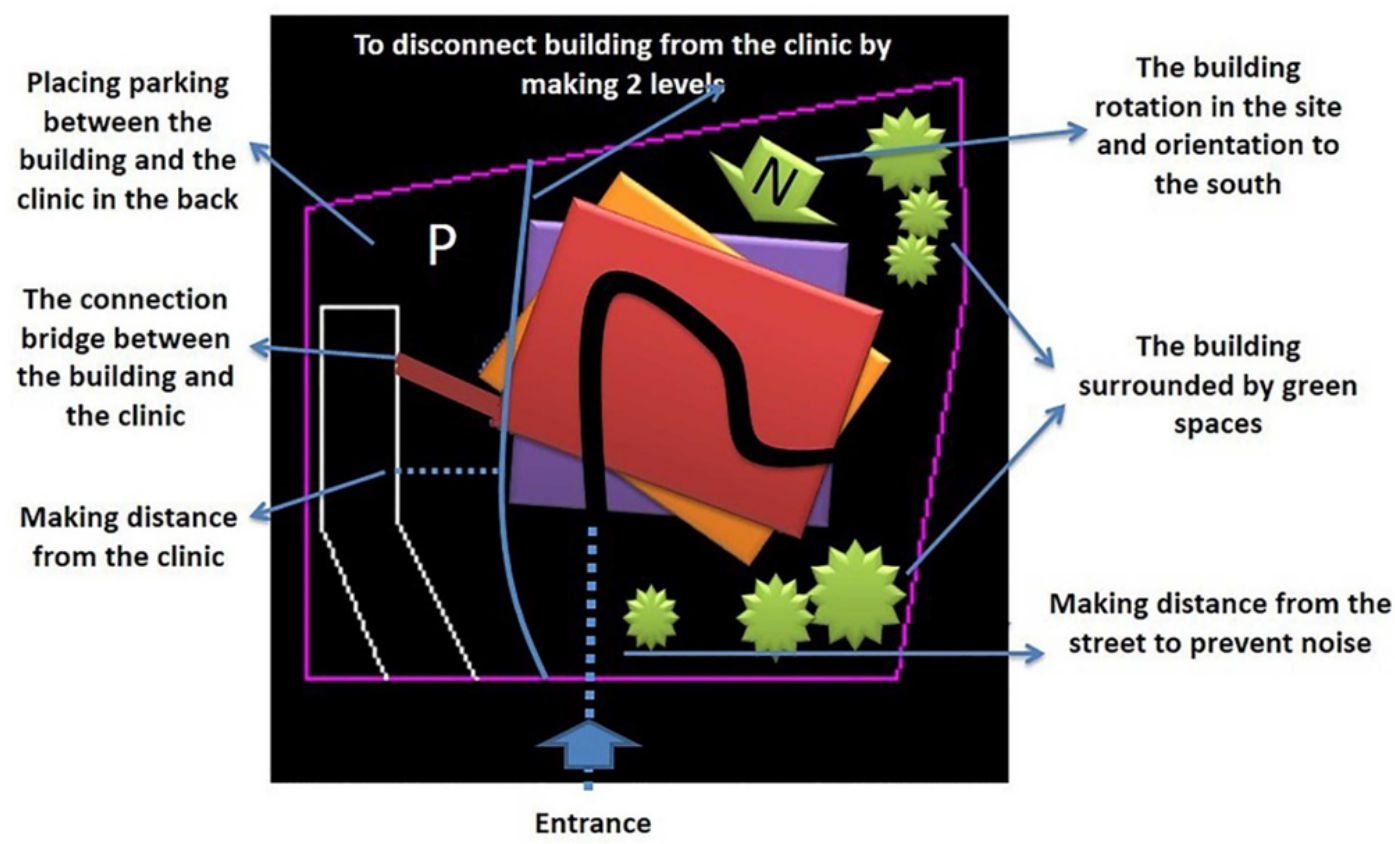

Figure 6. The Location Diagram of Site Studies

\section{Conclusion}

The research indicates that designing the complex as a house in the middle of the neighborhood park allows for children's presence in the society among the people and close interaction with people through being positioned in a neighborhood park, as well as providing the presence of the children in a space similar to a house which is every child's wish. On neighborhood scale, the park protects the children from social damages so that they feel sense of intimacy working between them and people. Additionally, with natural attractions for people, the place allows for an opportunity for physical recreation and spending leisure time in special days in a week, visit to exhibition as well as meeting children and establishing a close relationship with them; by doing so, it can raise the households' awareness of complying with scientific and sanitary standards and prevention of disability in children.

Factors whose prevention will no longer rob any child like them of the gift of health and being with family. The result is in line with Oldham and Beresford (1998) and Noyes (2002) and Mohammadi, who stressed the living of the children in home environment and providing good conditions for their lives in this environment. Likewise, 
Farjad (2014) and Jalilian (1999) and Tafazoli (2000) confirm the need for connecting children with society through integration of the living space of the children into the center of urban neighborhoods.

The Concept of Transformation of Institute Building to a House in The Middle of Local Park Show in Figure 7.
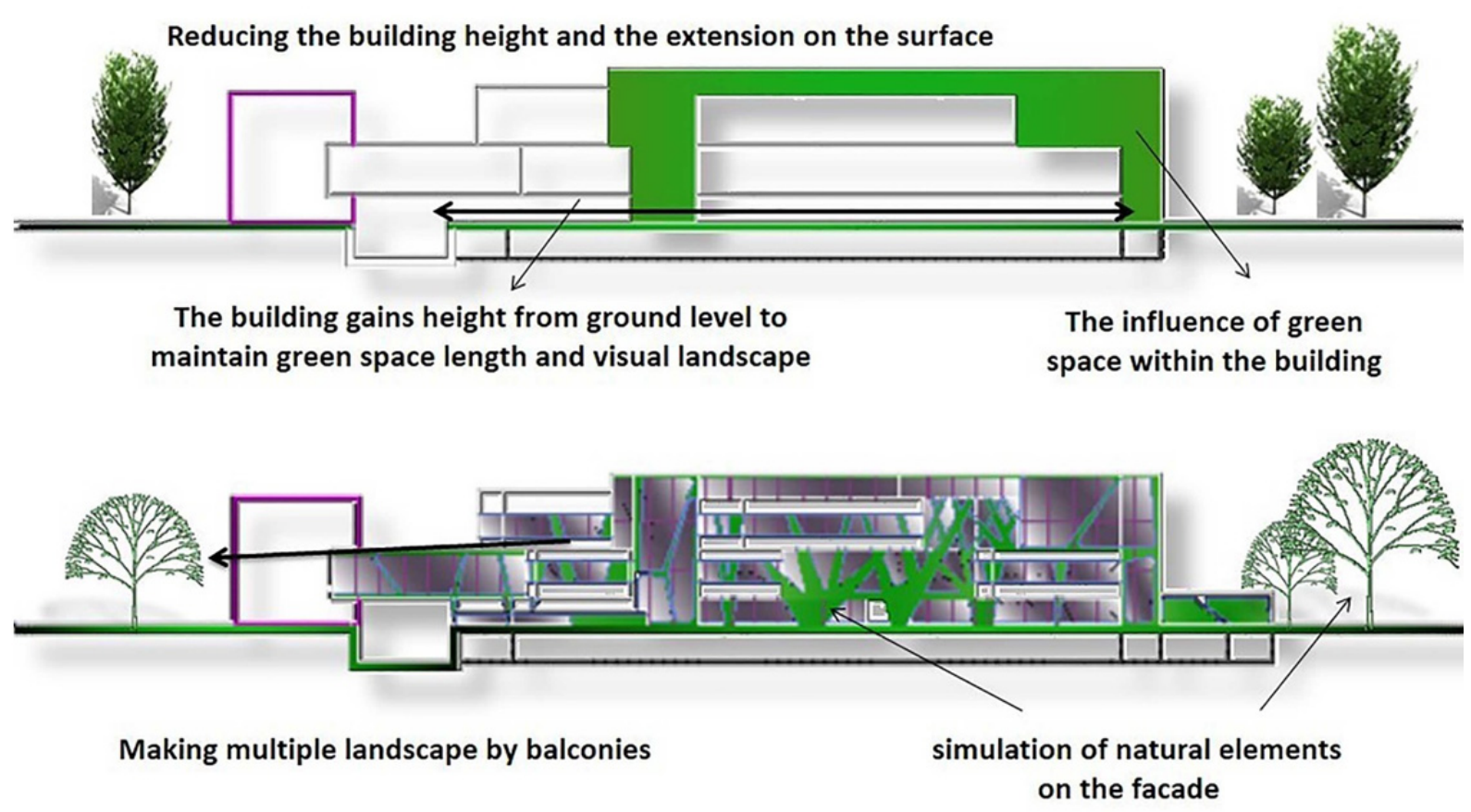

Figure 7. The Concept of Transformation of Institute Building to a House in The Middle of Local Park

To achieve the goal of this paper, i.e. establishing better relationship and interaction of the disabled children with social members with regard to lack of a caretaker and household, some strategies are offered in the form of four main strategies.

Strategies to Achieve Goals and Objectives Show in Table 1.

Table 1. Strategies to Achieve Goals and Objectives

\begin{tabular}{ll}
\hline Goal & $\begin{array}{l}\text { Establishing better relationship and interaction of disabled children } \\
\text { with social members in the face of lack of caretaker and family }\end{array}$ \\
\hline Strategies & solution \\
\hline & $\begin{array}{l}\text { designing a natural and green spaces in a way that it seems like an } \\
\text { invitation form } \\
\text { open space application should be in a way that the entire family can } \\
\text { take advantage of } \\
\text { indoor and outdoor spaces have provide calm and pleasant state }\end{array}$ \\
& $\begin{array}{l}\text { Spaces should be in a way that family find themselves to be part of the } \\
\text { system and big family }\end{array}$ \\
Promotion of the attractive feature of & $\begin{array}{l}\text { Hierarchy of space design should be in a way that it has an invitational } \\
\text { feature, and introduces the system, and then individual feel himself to } \\
\text { the complex in order to appeal } \\
\text { families and committed persons }\end{array}$ \\
& $\begin{array}{l}\text { Interior design should be cheerful and attractive so that individuals } \\
\text { never meet children with sad and pitiful face }\end{array}$ \\
& $\begin{array}{l}\text { Removing standard and conventional details of any sort and } \\
\text { everything that associate the building with a sense of organization or } \\
\text { institution. } \\
\text { The maximum effort should be made to normalize the design of }\end{array}$ \\
\hline
\end{tabular}




\section{interior spaces}

Setting spaces inside or outside in order to establish children's direct relationship with individuals

Using trained parents (including children's parents everyday) in order to educate the children of the institution and collaboration with mentors or volunteer individuals

Increasing the quality of visual face of the complex from external view
Reducing the height of the building as it sits on the site Let the building appear to be part of green spaces around itself

Sending educable children to exceptional student schools outside the complex so that there would be a chance to build a relationship to outdoor world and they never seem like isolated creatures

Preparing children for meeting social Sharing life experiences of the world outside the system by simulating members and vice versa

Providing people with essential recognition and preparedness to meet children and educate how relationship is formed through bulletins and display boards mounted on entrance spaces, etc.

Preventing the causes that lead to damage, harassment, humiliation, derision, ethical problems and deviation of children in communicating

Complex should be able to work in a with people

useful and effective way in the society complex by developing an appropriate design and space efficiency Providing programs, exhibitions, conferences, and charity mall inside the complex and public invitation to visit

Management, planning, and proper administration of the complex in such a way that it serves its function properly

\section{Acknowledgments}

Thank and gratitude to Rofaydeh Welfare Services Complex and all persons who assist and cooperate to data collection, which contributed to the success of my work.

\section{References}

Anaby, D., Hand, C., Bradley, L., DiRezze, B., Forhan, M., DiGiacomo, A., \& Law, M. (2013). The effect of the environment on participation of children and youth with disabilities: A scoping review. Disability and Rehabilitation, 35(19), 1589-1598. http://dx.doi.org/10.3109/09638288.2012.748840

Beresford, B. (2006). Housing and Disabled Children: a review of policy levers and opportunities. York: Social Policy Research Unit. University of York.

Borjian, M., \& Joghtaee, B. (2009). Proper standards of building and urban environment construction (for people with disability). Tehran: National Welfare Organization.

Farjad, S. (2014). Techniques of child care and protection. Tehran: Iran Textbook Publication Company.

Ghanbari-Hashemabadi, B. (2011). Comparing the emotional intelligence of orphanage children with ordinary children. Quarterly Educational Psychology, 7(21), 73-89. Retrieved from http://en.journals.sid.ir/ViewPaper.aspx?ID=252380

Hamm, S. (1999). Society and Children with Disabilities. IU Technology Toastmaster's Speeches.

Heywood, F. (2004). The health outcomes of housing adaptations, Disability \& Society, 19(2), $129-143$. http://dx.doi.org/10.1080/0968759042000181767

I have a house in the city, accommodation space suitable for abandoned children and teenagers. (2014). The first national conference on Urbanity, Urban Management, and Sustainable Development.

Jalilian, Sh. (1999). Spaces for the life of abandoned children in being integrated into urban neighborhood center. Master's thesis in Architecture, Shahid Beheshti University, Tehran, Iran.

Janabadi, A. (2006). Mental retardation. Mental Health site.

Noyes, J. (2002). Barriers that delay children and young people who are dependent on mechanical ventilators 
from being discharged from hospital. Journal of Clinical Nursing, 11(1), $2-11$. http://dx.doi.org/10.1046/j.1365-2702.2002.00565.x

Oldham, C., \& Beresford, B. (1998). Homes unfit for children: Housing, disabled children and their families. Policy Press, Bristol.

Oldham, C., \& Beresford, B. (2000). Meeting the housing needs of disabled children: Identifying the problems and a practitioner's agenda for joint working. Housing, Care and Support, 3(1), 25-28. http://dx.doi.org/10.1108/14608790200000007

Panahi, S, M. (2003). Celebration of World Disabled People Day. Let's encourage a disabled student to move.

Sanatinia, A. (1991). On the route to judgment, a survey on abandoned children and how they are take care of. Tehran: National Welfare Organization.

Seyyedhashemi, S. (2010). Center for taking care of abandoned children with a focus on education. Master's thesis in architecture, University of Isfahan, Isfahan, Iran.

Sorensen, R. J. (1991). Architecture for the disabled. Translated by Habib, F. Tehran: Nashr-e Daneshgahi Markaz.

Tafazoliyazdi, A. (2000). I have a house in the city, accommodation and care units for abandoned children, Master's thesis in Architecture, Shahid Beheshti University, Tehran, Iran.

Tajoddini, L., \& Mosavi, Sh. (2006). Fitting living environment for physical-motional disabled people, a national conference on urban environment fitting.

The website of Iran Salamat. (2005). mentally retarded: Family's responsibilities. Retrieved from http://iransalamat.com/index.php?file=art\&operation=show\&id=2982

Verdonschot, M. M. L., De Witte, L. P., Reichrath, E., Buntinx, W. H. E., \& Curfs, L. M. G. (2009). Impact of environmental factors on community participation of persons with an intellectual disability: A systematic review. Journal of Intellectual Disability Research, 53(1), 54-64. http://dx.doi.org/10.1111/j.1365-2788.2008.01128.x

Winkelstein, W., \& Hockenberry, K. (2013). Wong's Nursing Care of Infants and Children (7th ed.).

\section{Copyrights}

Copyright for this article is retained by the author(s), with first publication rights granted to the journal.

This is an open-access article distributed under the terms and conditions of the Creative Commons Attribution license (http://creativecommons.org/licenses/by/3.0/). 